\title{
ESTUDIO DEL TALENTO Y LA BONDAD: DESDE EL PUNTO DE VISTA BIO-PSICO-SOCIO-ESPIRITUAL
}

\author{
Study of the talent and the goodness: from the point of view \\ bio-psycho-social-spiritual \\ Henry Bueno O. ${ }^{1}$ \\ Universidad Nacional Mayor de San Marcos, Lima, Perú \\ (Recibido el 15/03/2011 - Aceptado el 02/06/2011)
}

\begin{abstract}
RESUMEN
"Dios creó al hombre semejante a él", es la frase del Génesis que dirige el estudio del talento, simbolizando que poseemos la facultad de crear vida; "y al final vio que todo esto era bueno", es la cita bíblica que corresponde al valor de la bondad, señalando que para Dios toda obra de sus manos (y nosotros somos sus manos) es buena. Esta reflexión expresa por qué una Psicología del Sembrador debe nacer de la Espiritualidad Carismática Católica: renovando los saberes de la psico-educación, aprendizaje y enseñanza, partiendo de dos escenarios saludables articulados que la humanidad necesita valorar: las escuelas y las parroquias, que representan el micro y el macro sistema favorecedore, para vivir en la era de la globalización.
\end{abstract}

Palabras clave: Psicología del sembrador, espiritualidad carismática católica, micro- sistema, escuelas, macro-sistema, parroquias, era de la globalización.

\begin{abstract}
"God created man similar to him", is the sentence of Genesis that directs the study of the talent, symbolizing that we have the power to create life; "and in the end saw that all this was good", is the biblical quote that corresponds to the value of the goodness, pointing out that Dios for any work of his hands (and we are his hands) is good. This reflection expresses a psychology of the sower must be born of the Catholic charismatic spirituality: renewing the knowledge of the psycho - education, teaching and learning. On the basis of two articulated healthy scenarios that humanity needs to assess: schools and parishes, which represent the micro and macro system favoring, to live in the era of globalization.
\end{abstract}

Keywords: Psychology of the sower, charismatic catholic spirituality, micro-system, schools, macro-system, parishes, age of globalization. 


\section{ANTECEDENTES}

La Psicopedagogía del Talento y la Bondad tiene una direccionalidad de afuera hacia adentro (que prospera con la acción formativa) eso implica que, corresponde justamente a una labor cooperante de una psico-educación de la creatividad y del amor que tiene una direccionalidad de adentro hacia afuera (que prospera con la actividad académica). Nada más cierto, claro está; razón por la cual es bueno apreciar ahora ¿Cómo desde la ficción, alimentado por algunas frases, se puede revelar frente a nosotros lo que ocurre en el contexto de dos sistemas de vida diferentes?; para comenzar nuestra discusión bastará con parafrasear la cosmovisión que nos presenta el Premio Nobel Peruano de Literatura desde "Cuatro siglos del Quijote" (Vargas Llosa, 2005) de esta forma daremos una primera aproximación a lo que ocurre en las escuelas y en las parroquias, lugares donde prioritariamente se enseña y se aprende:

Alonso Quijano, quien en un primer término nos hace rememorar a la figura de un aprendiz, tiene la percepción de lo real esencialmente falsa o mejor dicho, falseada por la ficción caballeresca (producida por su pobre experiencia de la vida, pero a su vez sacudida por los libros).

En cambio, al buen Sancho Panza (nos atrevemos a verlo como a un instructor académico), a quien, por su sentido común, por vivir anulado dentro de lo posible, se ha convertido en la encarnación de una deleznable humanidad, la del hombre en el que la materia sofoca al espíritu y cuyo horizonte vital es mezquino de tanto pragmatismo.

En segunda instancia y por el contrario un formador también es como un Quijote soñador, que enfundó la lanza de la pedagogía para sacar de la ignorancia a quien dentro de la novela de la vida se presenta como un chusco analfabeto, pero que desde el punto de vista social es un respetuoso ciudadano, mucho más respetuoso de la ley y del prójimo que su amo. No es culto como este, porque aún no ha aprendido a leer ni a escribir, pero está dotado de una inmensa sabiduría natural, perfeccionada en la dura escuela de la lucha por la supervivencia, que se vuelca, por momentos, en esa inagotable cantera de refranes, aprendidos en el hogar... y que pese a su ignorancia, es un espíritu abierto, al que la experiencia de la vida irá transformando.

Entonces, cabe hacernos más de una pregunta: ¿Qué tanto de Quijote o de Sancho hay en nuestros estudiantes cuando aprenden? Aún así, ¿cómo es posible que enseñen los profesores desde esa misma dicotomía? Y cuando entramos a la "Escuela de la Vida", ¿con qué recursos contamos docentes y participantes para responder al enigma de lo inalcanzable, el misterio de Dios con nosotros?; para descender finalmente a la pregunta principal: ¿qué papel juega la Psicopedagogía del Talento y la Bondad: junto a la psico-educación de la creatividad y del amor, en el marco del aprendizaje y la enseñanza? 


\section{PUNTOS DE VISTA PARA REFLEXIONAR ACERCA DEL TALENTO Y LA BONDAD, A LA LUZ DE LA CREATIVIDAD Y DEL AMOR; EN EL MARCO DEL APRENDIZAJE Y LA ENSEÑANZA}

1. Bio: Es el punto de vista referido a las características biológicas involucradas en la descripción-explicación de lo que ocurre con las personas.Etapas de Vida. Existen 8 etapas de vida marcadas que van desde la infancia hasta el adulto mayor, aunque vale decir que aquí la división que se plantea es meramente didáctica.

Adultos mayores. A partir de los 60 años en adelante.

Jóvenes adultos. De los 30 años hacia los 33 años.

Jóvenes. De los 19 años a los 29 años.

Adolescentes. De los 13 años a los 18 años.

Púberes. Desde los 10 años hasta los 12 años.

Niños. Desde los 6 años a los 9 años.

Infantes. Desde los 0 años hacia los 5 años.

Adultos. De los 34 años hasta los 59 años.

Relación con los Sacramentos. Para la Iglesia Católica, las etapas repasadas anteriormente guardan relación con Sacramentos que ayudan a la vida en gracia y esto a consecuencia de que la persona se encuentra confrontada casi siempre con el pecado y la muerte.

Extremaunción. Consiste en recibir los santos óleos cuando la condición de enfermedad o de edad atenta contra nuestra propia vida.

Matrimonio. Es la condición de vida aceptada libremente y en acuerdo con una pareja para vivir en sociedad y participar de la Iglesia como familia.

Penitencia. Se trata acerca de la aceptación de nuestros pecados y seguir humildemente el consejo sacerdotal para acercarnos a Cristo.

Confirmación. Es el sacramento en el que confirmamos nuestra adhesión a la creencia en la resurrección de nuestro señor y resucitamos con él al recibir su Santo Espíritu.

Confesión. Es el acto de compartir nuestro pecado de forma honesta con el sacerdote en la confianza y con la esperanza de ser perdonados.

Comunión. Consiste en recibir el cuerpo y la sangre de Cristo simbó-licamente a través del pan y el vino que es donde se haya presente por fe.

Bautismo. Es la forma de afiliarnos a la Iglesia Católica y de reconocer que somos Hijos de Dios.

Orden Sacerdotal.- Es la forma de vivir en comunidad elegida libre y espontáneamente para representar a un Cristo vivo ante los demás. 
2. Psico: Es el punto de vista referido a las características psicológicas involucradas en la descripción-explicación de lo que ocurre con las personas.

Inteligencias Múltiples. Son los fenómenos psicológicos superiores relacionados la facultad de crear productos desde la cultura a la que uno pertenece y como solución a un problema, para lo cual la persona se ha preparado perfeccionándose en el tiempo de manera consciente o inconsciente.

Corporal - kinestésica. Inteligencia donde interviene el movimiento y el dominio de las funciones orgánicas, sensitivas, reflejas y/o musculares principalmente; que llevan a la persona a sobresalir en el ámbito de la danza, los deportes, las artes marciales, etc.

Visual - espacial. Inteligencia que es parte del logro de la coordinación visomotora aplicada a la construcción de algún elemento del espacio; tiene que ver con los artistas plásticos, arquitectos, ingenieros, etc.

Lógico - matemático. Inteligencia que tiene que ver con sobresalir en las operaciones de cálculo aritmético, de razonamiento matemático, dominio de la lógica y relaciones de conjuntos y partes; es el caso de profesores de física, química, lógica, matemática, etc.

Verbal - lingüístico. Inteligencia que se destaca por el razonamiento verbal, dominio de las reglas de la gramática y la ortografía, las relaciones fonéticas y capacidad de hablar diversas lenguas; como lo tienen los profesores de letras, historia, geografía, idiomas, etc.

Intrapersonal. Se trata de personas que se conocen a sí mismas, lo que los hace poseedores de una capacidad de profunda reflexión, análisis y un rico mundo interior; hablamos de psicólogos, filósofos, religiosos, etc.

Interpersonal. Son personas que logran conocer a los demás, tienen gran carisma, pueden manejar grupos, así como las emociones; hablamos especialmente de psicoterapeutas.

Natural. O también llamada la inteligencia ecológica, pues obedece a la preocupación por temas de conservación del medio ambiente y de los organismos; tenemos en este caso a biólogos, médicos, agrónomos, etc.

Musical. Quienes poseen esta inteligencia leen partituras y/o de manera espontánea pueden tocar instrumentos musicales o cantar; así tenemos a cantantes solistas o de coro, flautistas, trompetistas, bateristas, cuenta cuentos, etc.

Personalidad. "Perfil”: desde la Psicología del Sembrador. Las diversas personalidades y perfiles citados a partir de los evangelios nos dan una clara idea de cuan relevante es ahora observar a las personas desde una Psicología Renovada por el Espíritu y así asumir para qué venimos realmente al mundo los creyentes.

Pablo, "El Apóstol". En los evangelios encontramos a un Pablo que como soldado romano había jurado perseguir a los cristianos, pero tras un encuentro personal con Cristo resucitado se convierte a la fe y es uno de los máximos representantes de ésta; en donde destaca como Apóstol, en el sentido que Dios le tiene preparada la misión de seguir a Cristo de cerca por donde vaya y ser su emisario en tierras lejanas al mundo civilizado. 
Tomás, "El Maestro". En los evangelios encontramos a un Tomás que como discípulo estuvo al lado de Jesús, pero que aún después de su resurrección tiene dudas sobre su fe y es uno de los hombres representantes de este dilema; en donde destaca como Maestro, en el sentido que Dios le tiene preparada la misión de seguir a Cristo como quien constantemente profundizará en su conocimiento acerca de él y no se dejará de preguntar.

Marcos, "El Evangelista". En los evangelios encontramos a un Marcos que como discípulo estuvo al lado de Jesús, tras la resurrección se convierte a la fe y es uno de los hombres representantes de ésta, en donde destaca su misión como evangelista, en el sentido que se le tiene preparado un camino en el que escribirá y hablará acerca de la buena noticia de la venida de Dios al mundo.

Pedro, "El Pastor". En los evangelios encontramos a un Pedro que como discípulo está al lado de Jesús, tras la resurrección se convierte en uno de los representantes de la naciente Iglesia en donde destaca como Pastor; en el sentido que le tiene preparada la misión de representar a Cristo guiando al pueblo a su encuentro personal con Dios.

Juan, "El Profeta". En los evangelios encontramos a un Juan que como discípulo está al lado de Jesús, tras la resurrección se convierte a la fe y es uno de los representantes desde su juventud donde destaca como profeta, en el sentido que Dios le tiene preparada la misión de revelar a Cristo en otros tiempos futuros y naciones por formar.

Mateo, "El Tradicionalista". En los evangelios encontramos a un Mateo que como discípulo está al lado de Jesús, tras la resurrección se convierte a la fe y es uno de los hombres que representa la tradición, en el sentido que Dios le tiene preparada la misión de anunciar a Cristo desde las costumbres de los hombres del pueblo de Dios y para comprender que hay un Cristo en todas las culturas y sociedades.

Lucas, "El Médico Sanador". En los evangelios encontramos a un Lucas que como discípulo está al lado de Jesús, tras la resurrección se convierte a la fe y es uno de los representantes de ésta; en donde destaca como sanador, en el sentido que Dios le tiene preparada la misión de anunciar que para curar a los enfermos basta creer en el médico de médicos que es Jesucristo.

Jesucristo, “El Salvador”. En los evangelios encontramos a un Jesús que se transfigura en Cristo en vida y que tras un encuentro personal con Dios Padre una vez resucitado es adoptado como el primero de sus Hijos (hecho que quedó registrado en la Sabana Santa y que hasta hoy no tiene explicación científica) y es uno de los máximos representantes de la fe de todos los hombres en donde destaca su misión como Salvador, en el sentido que Dios le preparó desde la eternidad para esa gran misión y así lavar nuestro pecado con su sangre preciosa.

3. Socio: Es el punto de vista referido a las características sociales involucradas en la descripción - explicación de lo que ocurre con las personas.

Micro - Sistemas de Vida Comunitario. Un Micro - Sistema es la expresión de la convivencia dentro de una parte importante de la comunidad (escuelas), en donde 
encontramos más que prácticas relacionadas a tareas específicas Vida Humana.

Escuelas. Son reguladas por los estados democráticos e intereses de organizaciones privadas y que albergan estudiantes, padres de familia, directores, personal administrativo y profesores para el logro de objetivos de enseñanza y aprendizaje de competencias.

Aulas. Es el espacio - tiempo donde se reúnen los principales actores (a saber estudiantes y profesores) para cumplir las tareas encomendadas, desde distintos niveles:

a) Superior

Post-grado

Pre-grado

b) Academia

c) Escolar

Secundaria

3. ${ }^{\text {ro }}, 4 .^{\text {to }}, 5 .^{\text {to }}$

Secundaria

$1 .^{\text {ro }}, 2 .^{\text {do }}$

Primaria

$1 .^{\text {ro }}-6 .^{\text {to }}$

d) Pre - escolar

Estimulación temprana, 3 años, 4 años, 5 años

e) Trabajo

Macro - Sistemas de Vida Comunitaria. Un Macro - Sistema es la expresión de la convivencia dentro de una parte importante de la comunidad (parroquias), en donde encontramos más que prácticas relacionadas a tareas específicas Vida Humana.

Parroquias o “Escuelas de la Vida”. Son reguladas por el estado Vaticano e intereses de organizaciones privadas y alberga a la iglesia peregrina (sacerdotes, laicos, magisterio de la iglesia, ministros, hermanos, etc.) para el logro de competencias como amar a Dios, a los hermanos como a uno mismo.

Grupos de oración. Es el espacio-tiempo donde se congregan los principales actores (a saber Magisterio de la Iglesia y hermanos) para cumplir las tareas encomendadas, por ejemplo:

a) Oración hablada 
b) Canciones espirituales

c) Experiencia de fe compartida

d) Alabanzas cantadas

e) Oración compartida por intercesión especial

f) Lectura de las escrituras

g) Silencio compartido

h) Palabra de Dios

4. Espiritual: Es el punto de vista referido a las características espirituales involucradas en la descripción-explicación de lo que ocurre con las personas.

Estado de Flujo Creativo. Es el planteamiento que observa el fenómeno creativo como un flujo energético en expansión constante que discurre de manera transversal desde los niveles bio-psico-social-espiritual permitiendo la interacción entre los seres humanos con una participación cada vez más consciente (Mihaly Csikszentmihalyi, 2008).

Aprender como Pablo, “El Apóstol”; con Inteligencia Corporal-Kinestésica. Podemos decir que Pablo aprendía mejor mientras recorría los distintos lugares por donde lo llevaba la fe en Cristo resucitado y usaba su cuerpo como un canal del amor de Dios.

Relación con la Educación: Acción Formativa. Es indudable por ello que guarde relación con la Educación, pues ésta en primera instancia es acción móvil.

Aleccionar como Tomás, "El Maestro"; con Inteligencia Visual - Espacial. Podemos decir que Tomás enseñaba mejor mientras reflexionaba cuestiones relacionadas con la fe en Cristo resucitado y usaba su mente como un canal del amor de Dios.

Relación con la Psicopedagogía: Talento y Bondad. Es indudable por ello que guarde relación con la Psicopedagogía, pues ésta es ampliamente preguntarse.

Anunciar como San Marcos, "El Evangelista"; con Inteligencia Lógico Matemático. Podemos decir que Marcos decía mejor mientras respondía lo que daba por cierto en fe respecto de la resurrección de nuestro señor y usaba su cerebro izquierdo como un canal del amor de Dios.

Relación con la Pedagogía: Actividad Académica. Es indudable por ello que guarde relación con la Pedagogía, pues esta es indudablemente dar solución a los problemas.

Aconsejar como San Pedro, "El Pastor"; con Inteligencia Verbal - Lingüístico. Podemos decir que Pedro orientaba mejor mientras se expresaba desde una fe nacida en Cristo resucitado y usaba su cerebro derecho como un canal del amor de Dios.

Psicología Educativa: Diagnóstico de la Realidad Peruana. Es indudable por ello que guarde relación con la Psicología Educativa, pues guarda relación con 
la expresión de la diversidad.

Advertir como San Juan, "El Profeta"; con Inteligencia Intrapersonal.Podemos decir que Juan prevenía mejor mientras lo que Cristo le revelaba desde la fe de su resurrección y usaba su corazón como un canal del amor de Dios.

Relación con la Psicología Vocacional. Es indudable por ello que guarde relación con la Psicología Vocacional pues podemos tomar decisiones y elegir libre responsablemente hacia dónde ir en nuestra vida.

Animar como San Mateo, “El Tradicionalista”; con Inteligencia Interpersonal. Podemos decir que Mateo estudiaba y conservaba mejor las costumbres mientras se relacionaba con los distintos pueblos por donde lo llevaba la fe en Cristo resucitado y usaba sus hábitos como un canal del amor de Dios.

Relación con la Psicología del Aprendizaje. Es indudable por ello que guarde relación con la Psicología de Aprendizaje en el sentido que pretendía ser un modelo de vida para los demás.

Aliviar como San Lucas, "El Médico Sanador"; con Inteligencia Natural. Podemos decir que Lucas curaba mejor mientras colocaba su confianza en Cristo resucitado y usaba su curiosidad como un canal del amor de Dios.

Relación con la Psicología del Lenguaje. Es indudable que por ello guarde relación con la Psicología del Lenguaje pues encontramos hoy en día en la terapia básicamente una relación profesional que parte de la amistad.

Anidar como Jesucristo, “El Salvador”; con Inteligencia Musical. Podemos decir que Jesucristo encajaba mejor en la historia bíblica y perdurará en el tiempo desde los sermones universales que daba a los demás y usaba parábolas como una forma de declarar el amor de Dios.

Relación con la Psico - educación: Creatividad y Amor. Es indudable por ello que guarde relación con la actividad psico-educativa desde el punto de vista que es la manifestación de una espiritualidad de todos los tiempos de las que beben distintas religiones en el mundo.

\section{Los Dones del Espíritu Santo}

Sabiduría. No es para que sepamos muchísimo de muchas cosas; sino para perfeccionar en nosotros ni más ni menos que el amor, la caridad. Las almas privilegiadas que de manera habitual han recibido ese don han amado a Dios como no tenemos ni idea; han aparecido ante el mundo como unos loquitos que eran capaces de hacer por Dios y por la gente gestos heroicos. Díganme si un misionero no necesita de este don del Espíritu Santo, cuando las exigencias de la Misión casi siempre, de manera habitual, han de ser heroicas.

Ciencia. Se trata de la ciencia verdadera, de la que viene y va a Dios en directo. Por supuesto que también perfecciona la fe que debemos transmitir a los demás, como el mejor servicio que se le puede prestar a los hombres, de acuerdo con Juan Pablo II. Esta ciencia nos enseña "a juzgar rectamente de las cosas creadas". El "hermano 
sol y la hermana luna" se las inventó el corazón de San Francisco de Asís con esta ciencia, que merece la vida entera por conocerla y gustarla. El misionero vive en pleno contacto con la naturaleza y sus maravillas; y todo le ayuda para entender mejor el amor de Dios y explicárselo con fuego a quienes nunca supieron que tenían en los cielos un Padre bondadoso que es puro amor.

Entendimiento. Potencia y cómo que dispara la virtud de la fe. Con él se entienden de manera admirable lo más profundos misterios; se comprende por ejemplo la santidad de la Virgen María; la grandeza de la Santa Misa, y su valor infinito... por medio de ese admirable don se ilumina nuestro entendimiento y nos confiere una fuerza y una eficacia santificadora, tal como la necesita el evangelizador, el que se entrega a la causa estupenda de dar a conocer al mundo a Cristo el Señor, su Vida y su Evangelio; al que deja su vida en los campos de las misiones.

Consejo y/o servicio. Gracias, en buena parte, a este regalo del Espíritu los misioneros fueron a parar a territorios que ni sabían dónde quedaban en la geografía de los continentes o países. Allí fueron a dar con sus huesos y con su enorme carga de fe y de amor, guiados, quizá sin saberlo, por el consejo sutil y cierto del Espíritu Santo. Ayuda mucho, pero mucho, a esa virtud tan rara y muy pocas veces tomada en cuenta que es la prudencia, virtud casi desconocida y raras veces empleada en nuestro vivir y en nuestro actuar. Nuestras grandes determinaciones en la vida están o deben estar signadas por el don de Consejo, si es que no queremos fracasar con nuestras propias loqueras o nuestros criterios personales.

Piedad. No es expresamente para formar monaguillos piadosos -que tampoco debe ser cosa fácil- sino que con este don, el Espíritu nos hace descubrir a Dios como Padre y quererle con todas nuestras fuerzas; de paso nos estimula a querer a nuestros hermanos, como Teresa de Calcuta quería a los leprosos. Es la vida ordinaria del misionero. Gentes que no conocen de nada ni la entienden en su cultura ni saben de su idioma, y se fajan, sin embargo, a conocer, amar y ayudar en cuerpo y alma, a pequeños Cristos que se le han cruzado en el camino de su vocación misionera. El don de piedad actúa como un auténtico milagro en el corazón del misionero. (Cuando se habla del misionero, se entiende por igual de la misionera, de la persona consagrada o del laico comprometido. Los dones no tienen género. Son del Espíritu Santo y basta).

Fortaleza o esperanza. Se trata de una fuerza del Espíritu Santo que resiste y acomete según la necesidad del momento. Es bueno recordar que la fortaleza es una de las virtudes cardinales $i S e$ acuerda usted por dónde anda eso en el catecismo que estudió? Pues aunque no se acuerde nadie, ni lo tome demasiado en serio, el Espíritu Santo, sí; él concede una fuerza y un valor increíble a quienes asiste en los trances más difíciles de la vida. Necesitamos todos urgentemente y casi en cada momento, de esta fuerza única que resiste el mal; el que sacude al mundo y a sus gentes como un huracán y tiende a destruirlo y borrarlo del mapa de la vida. Resistir el mal y hacer siempre el bien, sin cansarnos como nos enseña San Pablo. Las causas de Dios son empinadas, costosas; exigen muchas veces la vida misma. Por algo la Iglesia creció con la sangre de sus mártires. Pura fortaleza de Dios; don bellísimo y absolutamente necesario en nuestros tiempos. 
Temor de Dios. También el temor es necesario; pero es un temor pleno de amor; es un susto justificado de perder la amistad de nuestro Padre Dios y de nuestro hermano Jesús. Un enamorado tiembla sólo con pensar en que puede perder a su amor; a la persona que es razón de su vida. Se trata de un temor filial, el temor de Dios. Por supuesto que, si al perder al Dios se pierde el cielo donde él habita con sus santos, se puede uno imaginar lo terrible que tiene que ocurrir en el corazón de un misionero, si después de una entrega heroica y sin límites se queda del lado de afuera. San Pablo lo sintió y debió temblar como la hoja en el árbol. Temía que predicando a los demás, él mismo pudiera ser borrado del libro de la vida. El don de temor es sano, muy digno de que lo tomemos en cuenta y de pedírselo al Espíritu Santo junto con los demás dones y regalos que él nos hace.

Fe y razón. O más conocido como el Don Absoluto del Amor busca poner en práctica todos los demás dones, para el hombre común solo es posible el Amor cuando la Fe y la Razón están unidas, ahí es cuando cree y vive la ilusión del encuentro con Dios, de esta forma es más fácil entregarse a la misión hacia los demás cuando se encuentra a sí mismo en la conjunción entre la Fe y la Razón, esto es comparable a la expresión: "Dios te tiene entre sus manos y escribió tu nombre desde la eternidad".

\section{A MODO DE CONCLUSIÓN}

Dios tiene la palabra respecto del destino que correrá nuestra vida; si con la religión hemos aprendido que la vida es bella, la ciencia debe conciliar ese camino respondiendo a la pregunta que se nos plantea: ¿Cómo ocurre todo esto buscando la verdad? Y a partir de tal cuestión confiadamente diremos que el hombre es capaz también de orientar su porvenir, refiriéndonos a la intensidad con la que vivirá su destino, con amor o con pasión.

\section{REFERENCIAS BIBLIOGRÁFICAS}

1. Csikszentmihalyi, Mihaly (2008). Fluir, la Óptima experiencia Psicológica. $13 .{ }^{\mathrm{a}} \mathrm{ed}$. Buenos Aires: Color Efe.

2. Torres A., Félix (2008). Sagrada Biblia: Ilustrada a todo color. Versión Latinoamericana. Bogotá: Conferencia Episcopal Colombiana.

3. Vargas Ll., Mario (2005). Los Cuatro Siglos del Quijote. Estudios Públicos, N. ${ }^{\circ}$ 100, 2005. Santiago de Chile: Centro de Estudios Públicos. 